\title{
Inrush Current Analysis Based on Fast Fourier Transform
}

\author{
Mochamad Ilham Zamzami ${ }^{1, a, *}$, Eka Prasetyono ${ }^{1, b}$, Dimas Okky Anggriawan ${ }^{1, c}$ and Mike Yuliana $^{1, d}$ \\ ${ }^{1}$ Departement of Electrical Engineering, Politeknik Elektronika Negeri Surabaya, Jl. Raya ITS, \\ Keputih Sukolilo 60111, Indonesia \\ a, ${ }^{*}$ ilhamzamzami18@gmail.com (Corresponding Author), ${ }^{\mathrm{b}}$ eka@pens.ac.id, ${ }^{\mathrm{c}}$ dimas@ pens.ac.id, ${ }^{\mathrm{d}}$ mieke@ pens.ac.id
}

\begin{abstract}
Advances in technology have caused the use of electricity to increase rapidly. With advances in technology, this is followed by the use of increasingly efficient electrical components or equipment. This more efficient electrical equipment causes the impedance of the component to be smaller, causing a surge in current when it is turned on. This current surge, if not followed by appropriate safety precautions, will be damage other components. Each load has different waveform characteristics and current transient peaks. For this reason, it is necessary to analyze the transient condition of a load to overcome this. This paper will explain the characteristics of the inrush current of the load due to ignition. There are three loads used in this study, namely resistive, capacitive and inductive loads. Then the use of this load is simulated by giving different ignition angle values, namely 0,60 , and 90 degrees. The analysis used is the Fast Fourier Transform (FFT) method which is a derivative of the Discrete Fourier Transform. The inrush current spectrum in this simulation is simulated using Simulink MATLAB with switching system modeling using TRIAC. This inrush current simulation data collection uses a sampling frequency of $100 \mathrm{Khz}$ and will be analyzed in the first of 5 cycles. For each load in this paper, the harmonic values for each ignition angle will be presented. The simulation results show that the inrush current is caused by the ignition angle value used and because of components that can deviate energy such as inductors and capacitors as well as components which at the time of starting have a low impedance value such as incandescent lamps. The simulation also shows that the use of switching components for setting the ignition angle causes an increase in the value of Total Harmonic Distortion (THD) but the peak current in the first cycle when the ignition angle is set decreases.
\end{abstract}

Keywords-Inrush Current, Harmonic Analysis, FFT, THD.

\section{Introduction}

Currently, electricity is a primary need for every human being because it is useful for making work easier. When using electricity, and energy injection is needed so that electrical equipment can be electrified. During this injection process, there will be a surge in current due to a sudden change in potential. This transient condition is widely used in various researches. Monitoring the load during load started on can also use transient analysis [1]. different conditions of damage to the transformer can be analyzed using the transient state [2]. Load monitoring to save energy use can use transient data [3]. Transient analysis is also used to design a component so that no damage occurs in the event of an unbalanced state or a sudden transition. For example, when a transformer is injected with a power source, an internal error will appear [2]. Starting current also can detected defect in rotor cage of motor induction[4]. So it is necessary to study to observe the transient conditions when the electrical equipment is first energized.

The condition of the inrush current when the electrical equipment is first energized is called the current inrush. such as some computer equipment, televisions, ballasts in lighting systems, motors, etc. when turned on there will be an inrush current whose value is greater than the current in steady-state [5]. This transient condition causes the appearance of harmonic signals and even causes these harmonic components to spread at steady-state conditions [6]. The magnitude of the inrush current is determined by parameters switching its. To see this, it can be done by direct testing or by simulation using a computer.

Several previous studies have discussed about the inrush current in transformers with different types of loads, but in this study the analysis is directly on the load.. The study analyzed the inrush current by varying the angle of ignition and using FFT analysis. The results show that the even harmonic spectrum is more dominant. In this paper, the inrush current characteristics 
of resistive, inductive, and capacitive loads will be explained. Inrush currents in inductive loads are common in industry. An example is at the time of switching on transformers and motors. In the inrush current transformer is influenced by the characteristics of the iron core [7]. Then the flux from the core is affected by saturation. The saturation of the transformer core causes this short spike [8]. But in this paper what will be discussed for an example about inductive load is an induction motor. When the capacitor is energized, it will change the voltage on the capacitor suddenly, causing a current surge [9]. This happens because the capacitor voltage cannot change instantly so the system will adjust the capacitor voltage. The time of transient occurrence depends on the capacitance value of the system [10]. The inrush current causes a voltage dip at the capacitor and can be the source of equipment failure [11]. Filters that use capacitors also cause current surges due to when the capacitor is given a voltage such as short-circuit conditions with a fast time [5]. Inrush current when the capacitor is charged is showing in Figure 2. Peak inrush currents can be up to ten times their nominal current and occur in up to a few milliseconds [10]. The occurrence of inrush current in a resistive load is occur due to that at the time of ignition it has a small resistance value and when induced the resistance value will increase slowly. This resistance increase is due to the fact that when a voltage is induced, the temperature will increase and the resistance value is directly proportional to the resistance value. However, this inrush current is very fast in less than $50 \mathrm{~ms}$ for low power loads [9]. The greater the system power, the longer the inrush current will also be greater.

In this paper, the system will test was developed using MATLAB by changing the angle of ignition at each load. The analysis in this paper will be carried out using a fast Fourier transform (FFT) for harmonic analysis in the first 5 cycles. This paper will be analysis the harmonic characteristic at each load.

\section{Research Methodology}

This paper will simulate the inrush current characteristics of several loads using MATLAB. In this system there is a switching component that is used to facilitate transient observations in this case inrush currents.

\section{A. Data collection}

The data from this simulation were sampled using a frequency of $100 \mathrm{Khz}$. The discrete data from this sampling will be processed with the Fast Fourier Transform (FFT) algorithm and will eventually produce a spectrum or amplitude in the frequency domain.

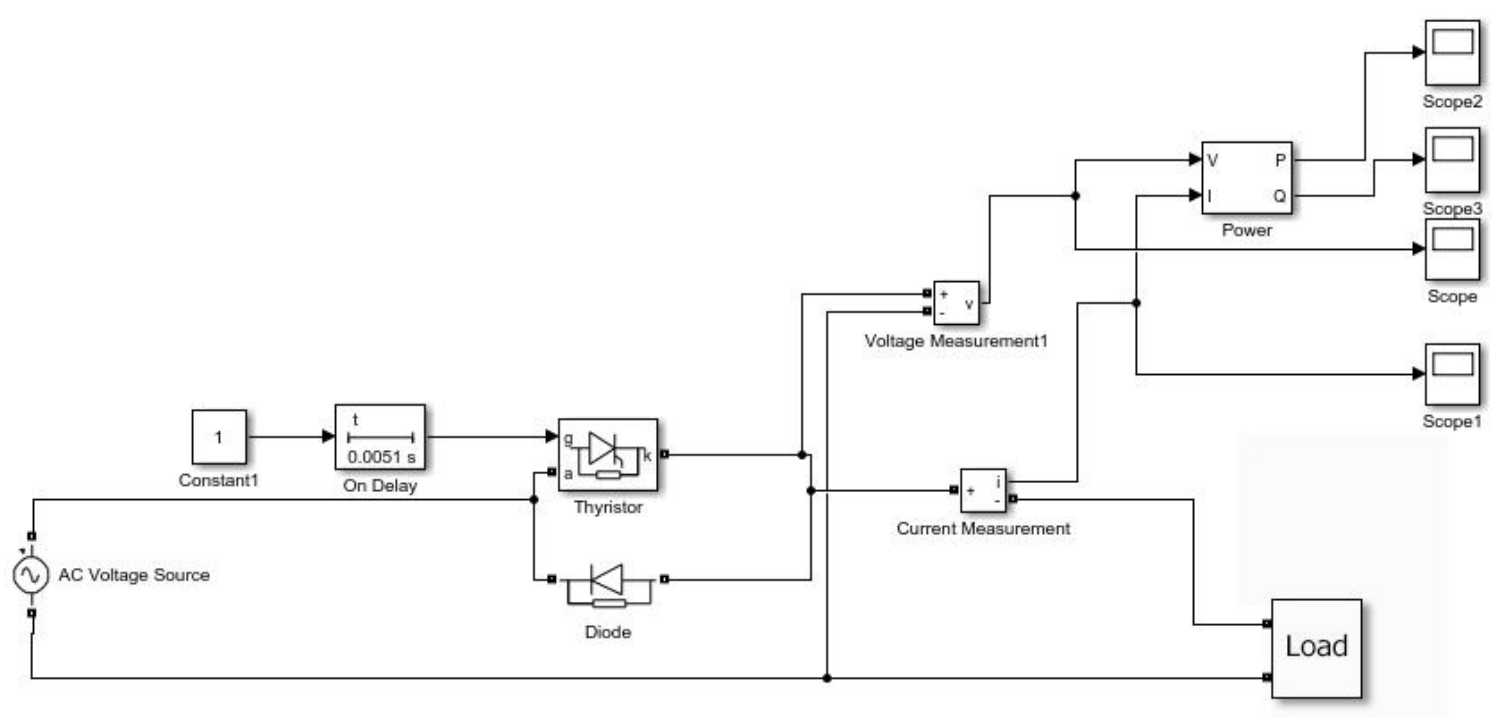

Figure 1 Block Diagram System 


\section{B. Diagram System}

In this observation, the instruction is only for a single phase load. The system design is as shown in Figure 1.

In the diagram there is a load block which will later be converted into several loads between the motor and transformer representing the inductive load, the rectifier load representing the capacitive load and the incandescent lamp representing the resistive load. In this tester there is a switching to change the angle of ignition of the voltage from the AC source. In this system a $220 \mathrm{~V}, 50 \mathrm{~Hz}$ source is provided. Harmonic observations are only carried out in 5 cycles or from zero to 0.1 second.

\section{Results and Discussion}

The inrush current by varying several inductive, capacitive and resistive loads can be observed using MATLAB. In this system, we will observe each load and compare the three types of loads by varying the angle of ignition on the load. Peak and harmonic currents will later be observed and analyzed.

\section{A. Inductive Load}

Analysing the transient condition of a $0.25 \mathrm{Hp}$ induction motor is conducted by comparing ignition angles of 0,60 and 90 degrees. The figure 2 shows the wave form and spectrum for 5 cycles.

Table 1. Simulation Result

\begin{tabular}{ccccc}
\hline \multirow{3}{*}{ Load } & \multirow{2}{*}{$\begin{array}{c}\text { Angle } \\
\text { (degree) }\end{array}$} & \multicolumn{2}{c}{ Current } \\
& & \multicolumn{2}{c}{ RMS (Ampere) } & \multirow{2}{*}{ Eror } \\
\cline { 2 - 4 } & & Real & FFT & \\
\hline \multirow{3}{*}{ Inductive } & 0 & 46.06 & 45.82 & $0.52 \%$ \\
\cline { 2 - 4 } & 60 & 45.13 & 44.89 & $0.53 \%$ \\
\cline { 2 - 4 } Capacitive & 90 & 44.33 & 43.58 & $1.69 \%$ \\
\cline { 2 - 4 } & 0 & 44.37 & 44.05 & $0.72 \%$ \\
\hline \multirow{3}{*}{ Resistive } & 60 & 339.1 & 339.13 & $0.01 \%$ \\
\cline { 2 - 4 } & 90 & 389.8 & 389.86 & $0.02 \%$ \\
\cline { 2 - 4 } & 0 & 1.27 & 1.2 & $5.51 \%$ \\
\hline & 60 & 1.36 & 1.34 & $1.47 \%$ \\
\hline
\end{tabular}

From the figure it can be seen that in the inrush current there is a DC component which is indicated by the amplitude at a frequency of $0 \mathrm{~Hz}$.

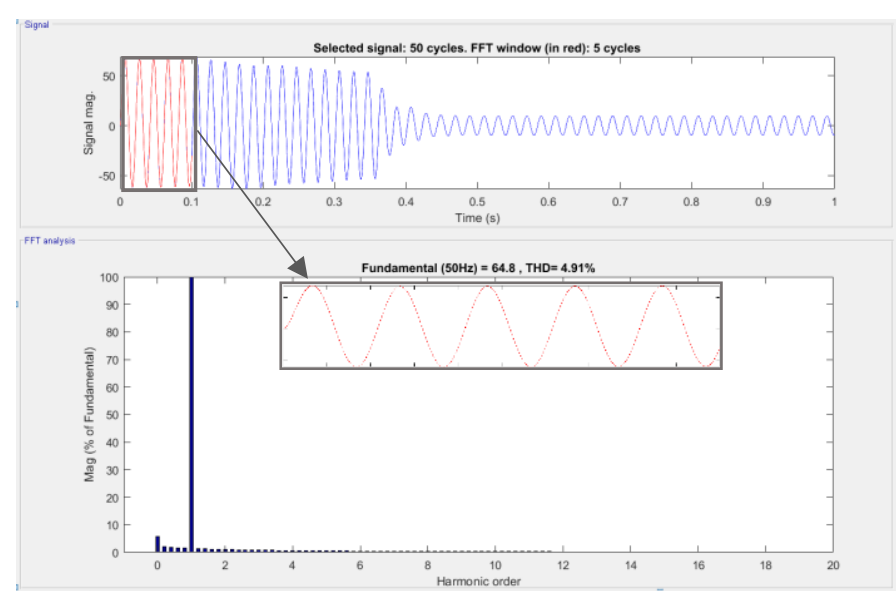

(a)

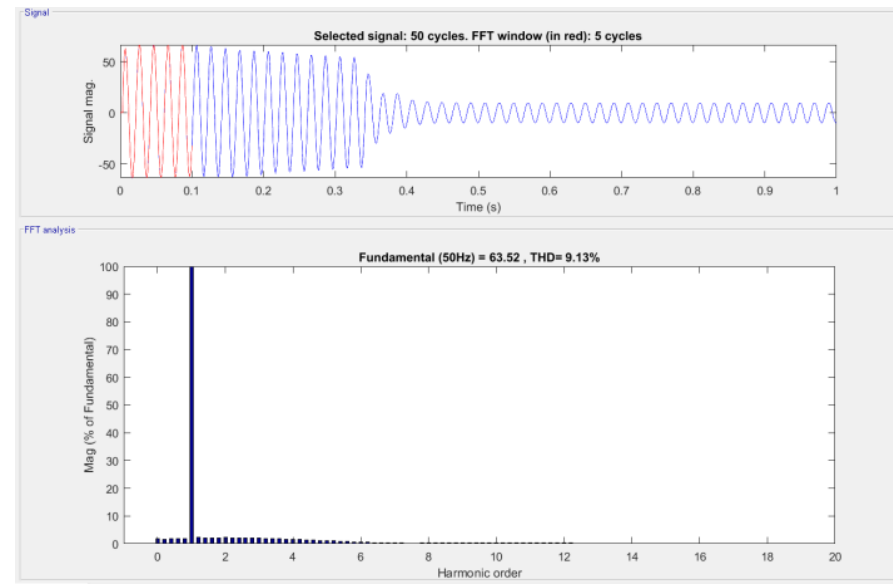

(b)

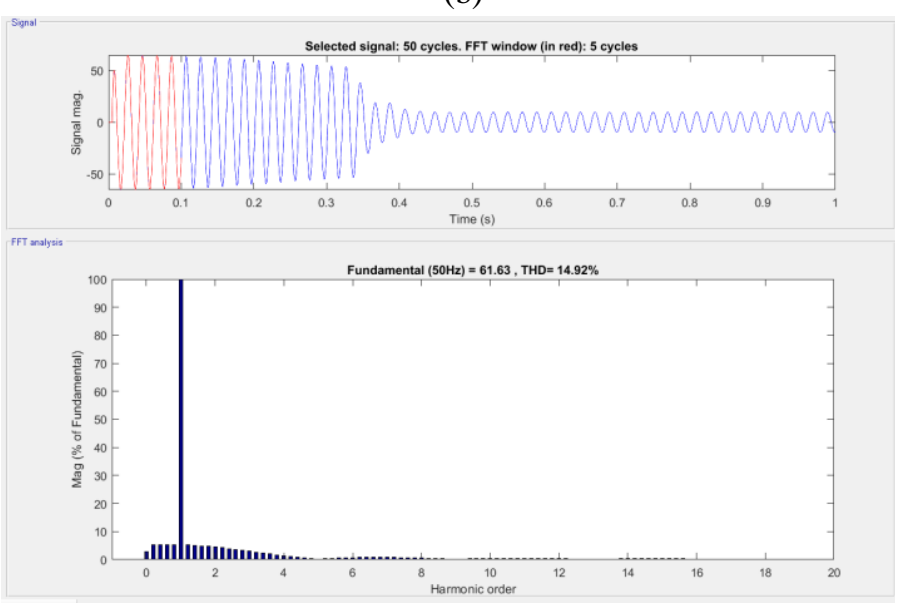

(c)

Figure 2. Inrush Current of Inductive Load With Ignition Angel: (a) $0^{\circ}$, (b) $60^{\circ}$, (c) $90^{\circ}$

This is because at the time of ignition, the inductive component still retains the residual flux from the previous system, so that when energized there is a 
sudden change in voltage causing an increase in current. As the harmonics orders increase, the amplitude of the high orders harmonics decreases, it is shown on the spectrum image. Then by differentiating the angle of ignition, the peak inrush current decreases in the first cycle and RMS value decrease in the first 5 cycles. This occurs due to a reduction in the value of the rms voltage in the first cycle due to the switching delay. Besides, setting the ignition angle causes an increase in harmonics seen from the value of the Total Harmonic Distortion (THD) which increases. This is due to the non-ideal switching components.

\section{B. Capacitive Load}

In this capacitive load, there will be a capacitor load added with a rectifier as the implementation of household loads that use DC loads so that a rectifier and capacitor are needed as filters so that the ripple from the DC source is small. In this simulation it is with a $1 \mathrm{mF}$ capacitor by varying the ignition angle from 0,60 and 90 degrees. At the capacitor load, odd harmonics will appear and the greater the harmonic value the amplitude will be down. Then when the ignition angle is set it causes the harmonic values to increase. This is due to the switching of the TRIAC component which causes a spike in the current. It can be seen that the inrush current in the first cycle when the ignition angle is set is very large. At an ignition angle of 0 degrees, the value of the inrush current in the first cycle is greater than in the other cycles. The momentary increase was due to the capacitor component used as a filter still deviating energy and when discharge to a resistive load there were still remnants of electrons. Therefore, when the next switching-on occurs, it causes the spike.

The peak value of this inrush is influenced by the size of the capacitor and resistor components in the system. When the resistor value is able to channel electrons from the capacitor discharge process, the current surge will decrease. However, when the value of the capacitor is large, it causes the inrush current in the first cycle to be very large as shown in Figure 3. So what affect the inrush current from the switching capacitor are the switching component and the value of the capacitor used.

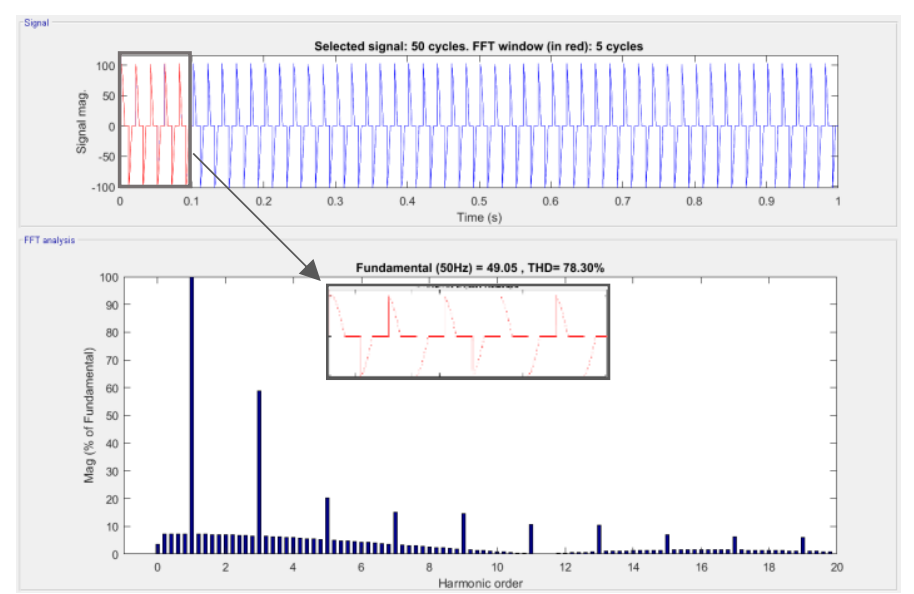

(a)

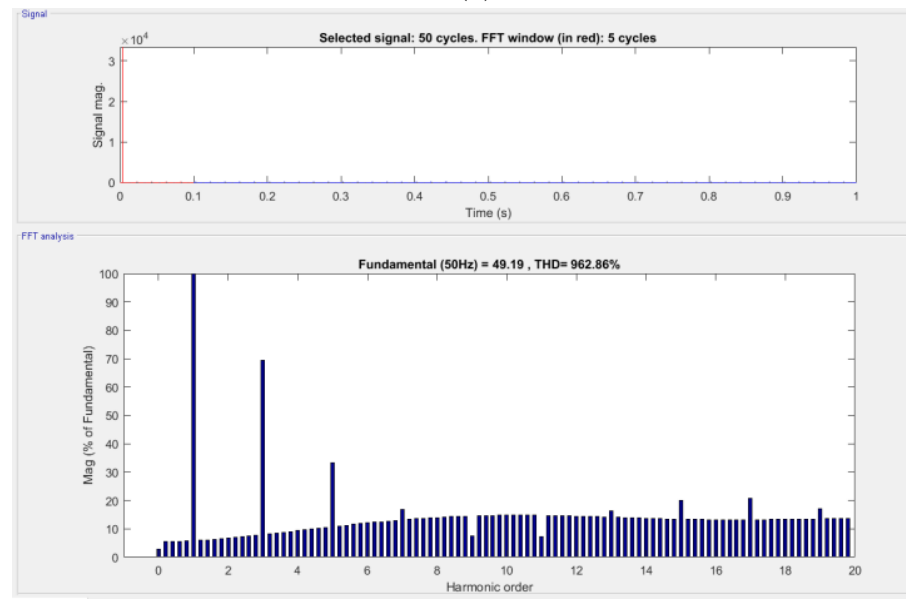

(b)

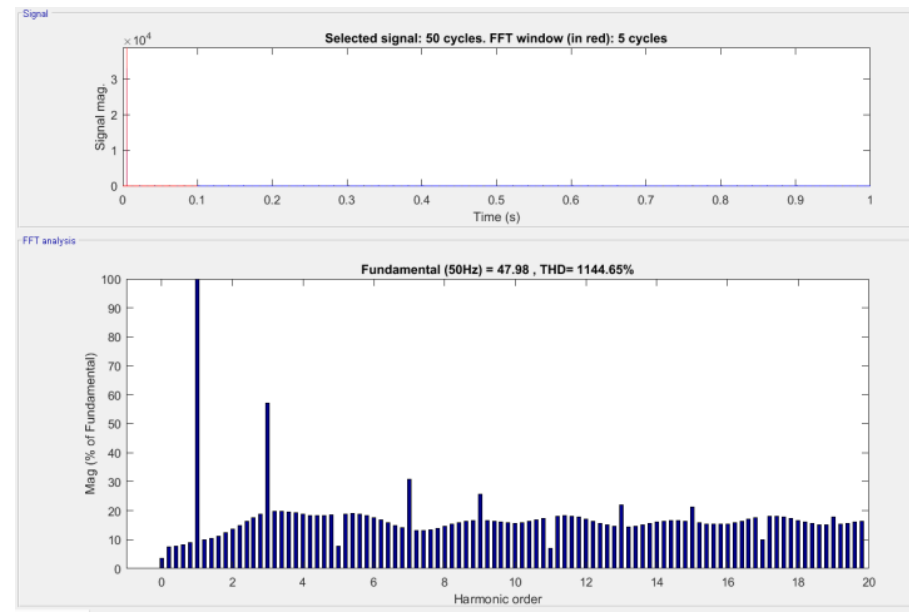

(c)

Figure 3. Inrush Current of Capacitive Load with Ignition Angle: (a) $0^{\circ}$, (b) $60^{\circ}$, (c) $90^{\circ}$ 


\section{Resistive Load}

The last is to test the light bulb which represents the inrush current from the resistive load. In this test is to use three light bulbs with different ignition angles of 0.60 and 90 degrees with a lamp power of 200 watts.

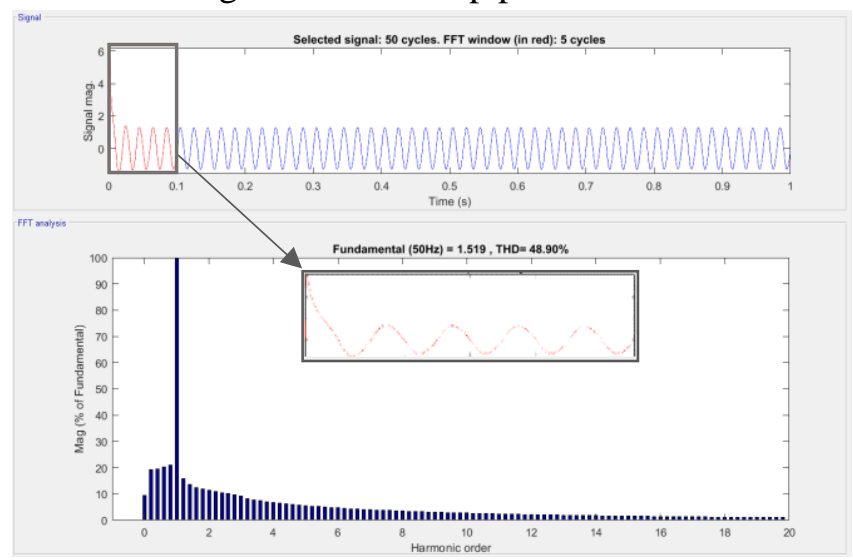

(a)

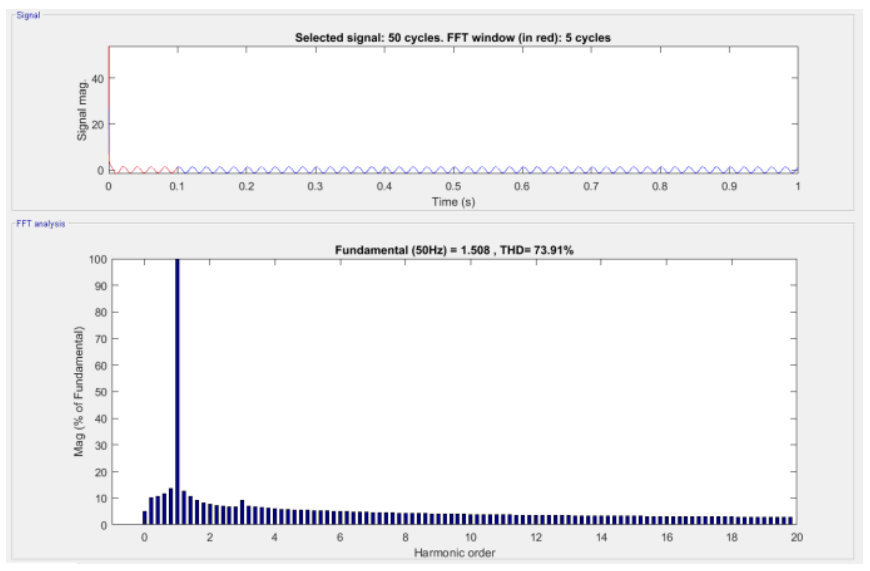

(b)

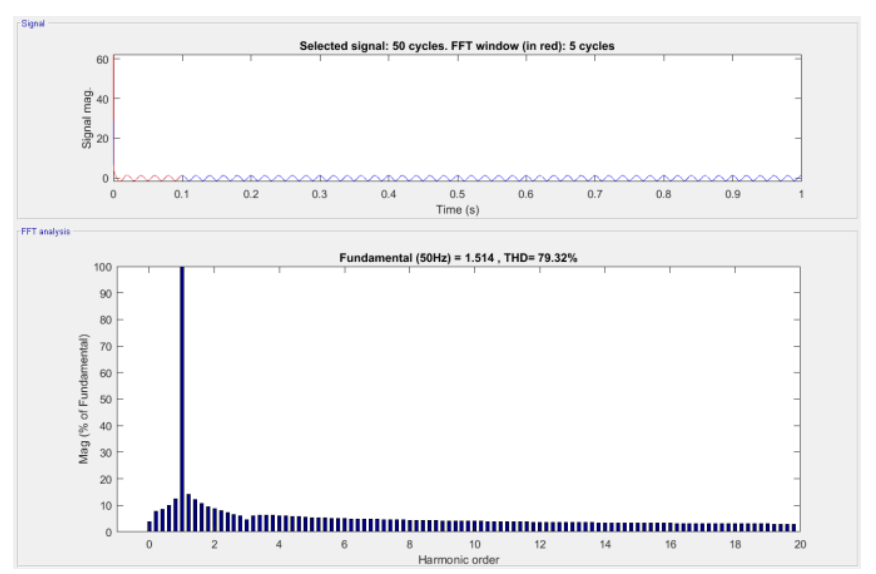

(c)

Figure 4. Inrush Current of Resistive Load with Ignition angle: (a) $0^{0}$, (b) $60^{\circ}$, (c) $90^{\circ}$
The resistive load in this simulation is represented by a light bulb. Harmonics orders in the first five cycles have harmonics. As can be seen in figure 4 , between the zero frequency and the fundamental frequency has an amplitude value where it shows that the DC component when the resistive load is injected is large and will decrease until it is in a steady-state. Then the larger harmonic order shows the lower the amplitude. By comparing the ignition angle, it can be seen that the THD value is increasing, but the amplitude of the DC component with an increase in the firing angle is getting smaller as shown in Figure 4. The cause of this is the initial condition or resistance value of the lamp when it is off. Because it is known that the resistance value is directly proportional to the temperature value of the resistance. When first turned on it has a very small resistance value causing a large inrush current. This initial value determines the peak inrush current in the first cycle. By comparing the ignition angle, it can be seen that the THD value is increasing, but the amplitude of the DC component with an increase in the ignition angle is getting smaller as shown in Figure 4.

Then according to the principle of the lamp when a source is given, there is an increase in temperature. As has been explained that the temperature is directly proportional to the resistance value, so when the source continues to be given, the resistance value will decrease until it reaches a steady state. At that time followed by a decrease in the inrush current in this load. Another thing that affects the inrush current from this resistive load is the temperature coefficient of the filament-forming component of the bulb. The increase in current occurs very briefly as shown in Figure 7 only in the first cycle. This occurs due to the increase in temperature followed by a decrease in the resistance value occurs very briefly.

\section{Conclusion}

Based on the simulation data and analysis that has been done, the amount of inrush current in each load is caused by several things. The inductive load is caused by the residual flux contained in the inductance of the system. For capacitive loads, this is because the capacitor can deviate energy so that when switching 
causes a current surge. And the resistive load is caused by a small initial resistance value. From this can conclude that the amplitude of depending on the total value of the system impedance and the impedance at the time of starting. Form calculating the average value of error, shows that inrush current calculation using this method has an accuracy $98.76 \%$.

\section{Acknowledgement}

We would like to thank many of lectures and students who contribute greatly for this research where we could not be able to mentioning in this part. This research is financially supported by Politeknik Elektronika Negeri Surabaya.

\section{References}

[1] H. H. Chang, C. L. Lin, and J. K. Lee, "Load identification in nonintrusive load monitoring using steady-state and turn-on transient energy algorithms," Proc. 2010 14th Int. Conf. Comput. Support. Coop. Work Des. CSCWD 2010, pp. 27-32, 2010, doi: 10.1109/CSCWD.2010.5472008.

[2] J. Ma, Z. Wang, Q. Yang, and Y. Liu, "A two terminal network-based method for discrimination between internal faults and inrush currents," IEEE Trans. Power Deliv., Vol. 25, No. 3, pp. 1599-1605, 2010, doi: 10.1109/TPWRD.2009.2036262.

[3] V. Rathore and S. K. Jain, "Non Intrusive Load Monitoring and
Load Disaggregation using Transient Data Analysis," 2018 Conf. Inf. Commun. Technol. CICT 2018, pp. 1-5, 2018, doi: 10.1109/INFOCOMTECH.2018.8722382.

[4] C. Yang et al., "Starting current analysis in medium voltage induction motors: Detecting rotor faults and reactor starting defects," IEEE Ind. Appl. Mag., Vol. 25, No. 6, pp. 69-79, 2019, doi: 10.1109/MIAS.2019.2923105.

[5] Y. A. Mobarak and M. M. Hussein, "Voltage instability and voltage collapse as influenced by cold inrush current," ICGST Int. J. Autom. Control Syst. Eng., Vol. 12, No. 1, pp. 21-30, 2012.

[6] Nait-Meziane, M., Ravier, P., Abed-Meraim, K. et al. Electrical transient modeling for appliance characterization. EURASIP J. Adv. Signal Process. Vol. 55.2019. https://doi.org/10.1186/s13634-019-0644-2

[7] J. H. Harlow, Electric power transformer engineering : electric power engineering handbook, 2nd ed. California: CRC Press, 2007.

[8] S. J. Champan, Electric Machinery Fundamental: Fourth Edition, 4th ed. New York: McGraw-Hill Education, 2005.

[9] R. E. Fehr, Industrial power distribution, Second. New Jersey: IEEE PRESS, 2016.

[10] G. Olivier, I. Mougharbel, and G. Dobson-Mack, "Minimal Transient Switching Of Capacitors," IEEE Trans. Power Deliv., Vol. 8, No. 4, pp. 1988-1994, 1993, doi: 10.1109/61.248312.

[11] D. F. Peelo, "Capacitive Load Switching," Curr. Interruption Transients Calc., pp. 147-174, 2020, doi: 10.1002/9781119547273.ch7. 